Submission ID: 43883

\title{
Studying Fluids of the Domanic Deposits of the Republic of Tatarstan
}

I. Guskova (Almetyevsk State Petroleum Institute), L. Garipova (Almetyevsk State Petroleum Institute), A. Gabdrakhmanov* (Almetyevsk State Petroleum Institute)

\section{SUMMARY}

The problem of engaging in the development of oil shale deposits is becoming increasingly important all over the world. In the conditions of depletion and deterioration of the structure of reserves, the need for oil production does not decrease, on the contrary, it is steadily growing, therefore it is necessary to develop and introduce modern technologies for extraction of unconventional oil reserves.

The domanic deposits of the Volga-Ural oil and gas province are of special interest for studying their geological and physical characteristics.

In this paper, we present the results of laboratory studies based on the optical properties of oil from

Tatarstan's domanic deposits, as well as a comparative analysis of higher and lower-lying productive beds. Specific features of changing the properties of oil of various sediments were established. 


\section{К вопросу об исследовании флюидов доманиковых отложений Республики Татарстан}

И.А. Гуськова, А.Т. Габдрахманов ${ }^{*}$, Л.И. Гарипова (Альметьевский государственный нефтяной институт)

\section{Введение}

В последние годы по всему миру все большую актуальность приобретает проблема вовлечения в разработку месторождений сланцевой нефти. В условиях истощения и ухудшения структуры запасов потребность в добыче нефти не падает, наоборот, неуклонно растет, поэтому необходимо разрабатывать и внедрять современные технологии для извлечения нетрадиционных запасов нефти. Доманиковые отложения Волго-Уральской нефтегазоносной провинции представляют особый интерес по изучению их геолого-физической характеристики. В данной работе приведены результаты лабораторных исследований на основе оптических свойств нефти доманиковых отложений Татарстан, а также сравнительный анализ выше и нижезалегающих продуктивных пластов. Были установлены особенности изменения свойств нефти различных отложений [1].

Породы, известные как доманикиты или доманикоиды, являются потенциальным источникам углеводородов на территории Волго-Уральской нефтегазоносной провинции. Доманикиты представлены глинистыми, глинисто-карбонатными, кремнисто-глинисто-карбонатными и кремнистыми разностями пород. На территории востока Восточно-Европейской платформы доманикиты развиты в Пермской, Самарской областях, Татарстане и Башкортостане. К ним относят, содержащие рассеянное органическое вещество сапропелевого типа. Доманикиты представлены глинистыми, глинисто-карбонатными, кремнисто-глинисто-карбонатными и кремнистыми разностями пород. В данной работе были проанализированы свойства добываемой нефти из заволжских и данково-лебедянских отложений НГДУ «Бавлынефть». Проанализированные скважины НГДУ «Бавлынефть» эксплуатируются в основном с применением ГРП. ПАО «Татнефть» может обеспечить прирост запасов нефти за счёт сланцевой нефти в доманиковых отложениях во всех регионах, где работает компания. Сегодня в этом направлении активные работы на опытных скважинах проводят нефтегазодобывающие управления «Бавлынефть» и «Ямашнефть» в Татарстане, в Оренбургской и Самарской областях. Карбонатные коллектора относятся к трудноизвлекаемым залежам нефти в виду слабой проницаемости, неоднородной по строению геологической структуры, «тяжёлому» составу нефти. Поэтому традиционные методы для освоения этих пород не подходят. Необходимо создание отдельной системы разработки, системы поддержания пластового давления, новые методы обработки призабойных зон, гидравлических разрывов пластов [2].

\section{Описание оптического метода для анализа продукции скважин}

В лаборатории кафедры Разработки и эксплуатации нефтяных и газовых месторождений Альметьевского нефтяного института были исследованы оптические свойства проб нефти со скважин **44, **12, **41, эксплуатирующих доманиковые отложения НГДУ «Бавлынефть». Плотность нефти, добываемой этими скважинами, варьирует от $896 \mathrm{\kappa г} / \mathrm{m}^{3}$ до $941 \mathrm{\kappa} / \mathrm{m}^{3}$, содержание асфальтенов от $3,21 \%$ до $15,18 \%$, парафинов от 1,35 до 5,55 \%, смол от $14,3 \%$ до $37,31 \%$ и сильно меняется в динамике.

Спектрофотометрические методы анализа на протяжении нескольких десятилетий достаточно широко использовали в промысловой практике для решения ряда задач разработки нефтяных месторождений. Фотоколориметры и спектрофотометры, работающие в видимой и ближней ультрафиолетовой и ближней инфракрасной областях светоизлучения позволяют определить оптическую плотность - параметр, характеризующей способность вещества поглощать свет и затем получить пересчётный параметр. Коэффициент светопоглощения нефти зависит от содержания в нефти асфальтенов и смол и определяется из закона Бугера - Ламберта - Бера и не зависит от концентрации нефти в растворителе и толщины слоя нефтяного раствора. 


$$
K c n=\frac{D}{0,4343 \cdot c \cdot l}
$$

где $K_{c n}-$ коэффициент пропорциональности, называемый коэффициентом поглощения или коэффициентом экстинкции вещества, $\mathrm{cm}^{-1} ; D$ - оптическая плотность является безразмерной величиной (или измеряется в Белах); $c$ - концентрация нефти в растворителе, доли единиц или проценты; $l$ - длина оптического пути, см.

По оптической плотности среды, которая может быть охарактеризована показателем поглощения, можно судить о групповом углеводородном составе нефти и нефтяных дистиллятов. К настоящему моменту времени накоплен большой опыт применения этих методов для контроля процессов разработки нефтяных месторождений.

Впервые спектрофотометрический метод контроля за разработкой нефтяных месторождений, использованный для определения закономерностей распределения коэффициента светопоглощения нефти, был применён в 1960 году И.Ф.Глумовым и А.Ф.Гильманшиным. Исследования проводились на Ромашкинском и Бавлинском месторождениях [3]. Основные этапы исследования применения оптических методов исследования нефти Республики Татарстан представлены в работах $[3,4,5,6,7]$. Однако, учитывая, что по мере извлечения нефти характер распределения Kcn нефти по пласту становится всё менее закономерным, вышеперечисленные закономерности распределения коэффициента светопоглощения, в основном, характерны для ранних стадий разработки месторождения $[8,9]$.

\section{Результаты исследований продукции скважин, эксплуатирующих доманиковые отложения}

На рисунках 1-2 показана динамика дебита нефти, жидкости и обводненности по скважине **44, на которой был проведён ГРП в декабре 2013г. Видно, что после проведения ГРП дебит нефти увеличился с 2 т/сут до 8-10 т/сут - более чем в 4 раза. При этом обводненность продукции скважины **44 уменьшилась почти в 3 раза. Таким образом, ГРП оказался успешным.

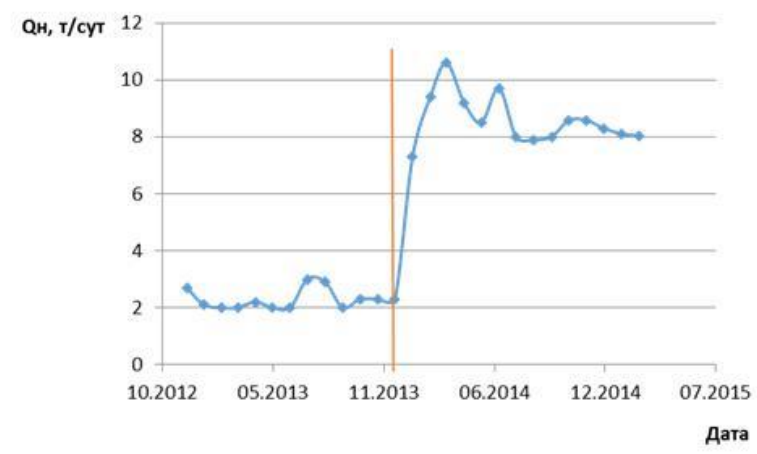

Рисунок 1 Динамика дебита нефти до и после проведения ГРП на скважине **44

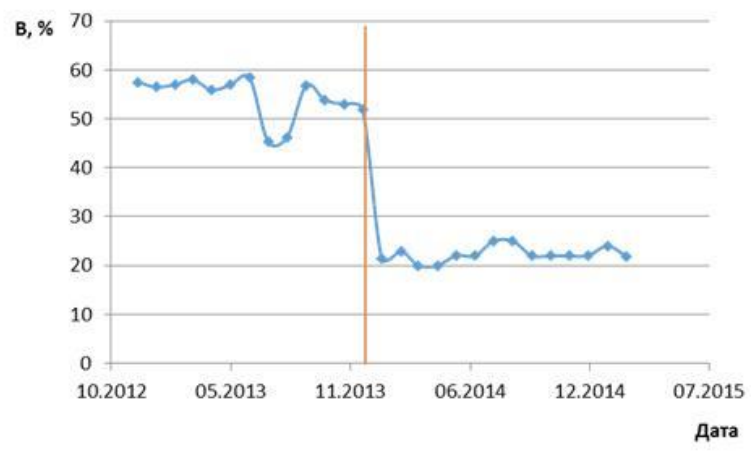


Рисунок 2 Динамика обводненности продукции до и после проведения ГРП на скважине **44

Для проб нефти со скважин $* * 44, * * 12, * * 41$, эксплуатирующих доманиковые отложения НГДУ «Бавлынефть», было установлено, что коэффициент светопоглощения нефти варьирует от 4061,13 1/см, до 3151,62 1/см при длине волны 385 нм.

При сопоставлении спектров поглощения данных проб можно заметить, что они имеют одинаковый характер и практически повторяют друг-друга. На рисунке 3 представлены спектр коэффициента светопоглощения нефти при длинах волн от 300 нм до 1100 нм для пашийских-кыновких отложений и осреднённый спектр в том же диапазоне для доманиковых отложений. В результате предварительных исследований также можно отметить, что существенных отличий в свойствах нефти пашийскихкыновских и доманиковых отложений также не наблюдается.

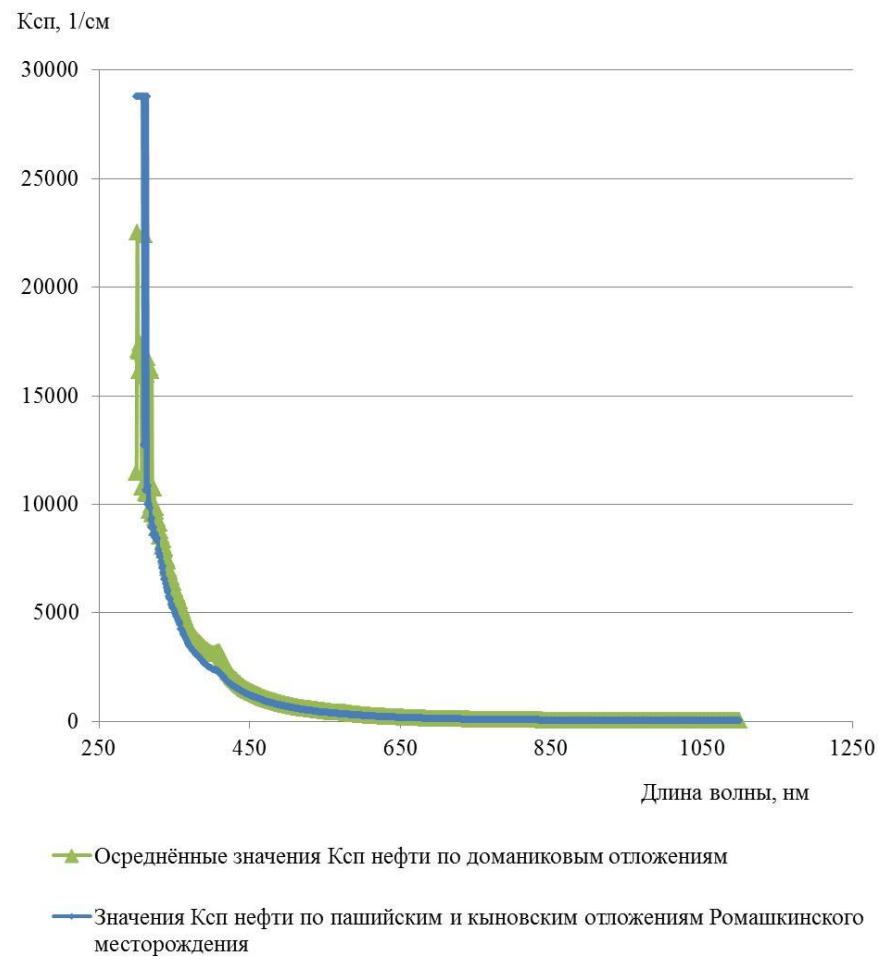

Рисунок 3 Спектры коэффициента светопоглощения нефти пашийско-кыновских и доманиковых отложений

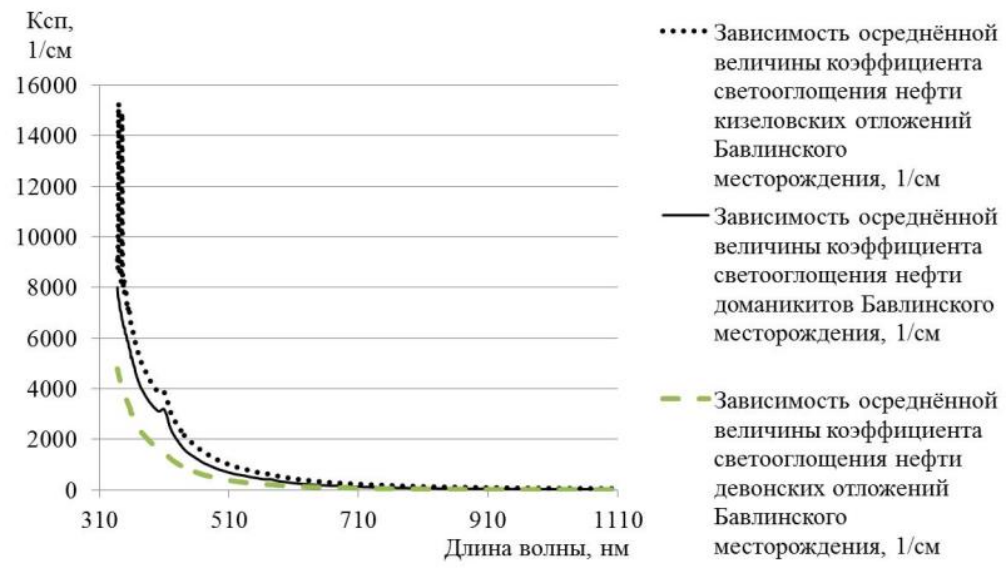

Рисунок 4 Зависимость осреднённых значений коэффициента светопоглощения нефти по кизеловским, доманиковым и девонским отложениям Бавлинского месторождения 
Если построить графики зависимости осреднённых значений коэффициента светопоглощения нефти в целом по кизеловским, доманиковым и девонским отложениям Бавлинского месторождения, можно отметить промежуточное положение оптической плотности нефти доманикитов, с более приближенными значениями кизеловских отложений (рисунок 4). Однако наличие пиков в спектрах поглощения добываемой нефти из кизеловских и доманиковых отложений может свидетельствовать о том, что эти нефти относятся к одному типу, в отличие от нефти девонских отложений.

\section{Выводы}

Результаты лабораторных исследований показали, что спектр поглощения нефти доманиковых отложений НГДУ «Бавлынефть» варьирует от 4061,13 1/см, до 3151,62 1/см. При этом, плотность нефти, добываемой этими скважинами, варьирует от $896 \mathrm{\kappa г} / \mathrm{m}^{3}$ до $941 \mathrm{\kappa} / \mathrm{m}^{3}$, содержание асфальтенов от 3,21 \% до $15,18 \%$, парафинов от 1,35 до 5,55 \%, смол от $14,3 \%$ до $37,31 \%$ и сильно меняется в динамике. С использованием анализа динамики работы было установлено, что технология ГРП позволила успешно добывать нефть из плотных коллекторов. Разработка данных коллекторов является перспективной, необходимо продолжить исследовательские и опытно-промышленные работы в данном направлении. В дальнейшем необходимо провести исследования динамики изменения свойств нефти в процессе разработки, что даст возможность исследования стабильности ее состава и преобразования в процессе разработки.

\section{Библиография}

1. Гуськова, И.А. Предварительная оценка результатов освоения залежей доманиковых отложений республики татарстан. И.А. Гуськова, А.Т. Габдрахманов, Е.В. Леванова, Р.И. Музипов. http://antat.tatar/ru/activity/conferences/documents/Soderganie.pdf (дата обращения 13.05.17)

2. Маликов, А. Ресурсы карбонатной нефти в Татарстане достигают 1 млрд тонн http://www.oilru.com/news/403690 (дата обращения 13.05.17).

3. Глумов, И.Ф. Временная инструкция по применению фотоколориметрии добываемых нефтей для решения геологопромысловых задач [текст] / И.Ф. Глумов, А.Ф. Гильманшин // Бугульма: ТатНИИ, 1965. - 37 с.

4. Гильманшин, А.Ф. Характер и причины изменения во времени величины $\mathrm{k}_{\text {сп }}$ добываемой нефти на Ромашкинском и Бавлинском месторождениях [текст] / А.Ф. Гильманшин // Труды ТатНИИ.-Ленинград: Недра, 1964.выпуск VI -С.281-291.

5. Девликамов В.В. Хабибуллин 3.А. Физика пласта: Учебное пособие .-Уфа. Изд. Уфимс. Нефт. Ин-та, 1986.-82с.

6. Ибатуллин, Р.Р. Увеличение нефтеотдачи на поздней стадии разработки месторождений [текст] / Р.Р. Ибатуллин, Н.Г. Ибрагимов, Ш.Ф. Тахаутдинов, Р.С. Хисамов // Теория. Методы. Практика.-М.: ООО «Недра-Бизнесцентр», 2004.-292с.

7. Девликамов, В.В. Оптические методы контроля за разработкой нефтяных месторождений [текст] / В.В. Девликамов, И.Л. Мархасин, Г.А. Бабалян // М.: Недра, 1970.$160 \mathrm{c}$.

8. Пат. 2429343 РФ, МПК Е21В 43/16. Способ разработки нефтяной залежи [текст] / Н.Г. Ибрагимов, И.А. Гуськова, Р.Р. Ибатуллин, А.Р. Рахманов, А.Т. Габдрахманов, М.В. Швецов; заявитель и патентообладатель ОАО «Татнефть» им. В.Д. Шашина. №2010142776/03; заявл. 20.10.10; опубл. 20.09.11, бюл. №26.

Гуськова, И.А. Исследование влияния применения методов увеличения нефтеотдачи пластов на изменение свойств добываемой нефти [текст] / И.А. Гуськова, А.Т. Габдрахманов // Нефтяное хозяйство. - 2011, №4. - С. 101-103.

8. Гуськова, И.А. Исследование влияния применения методов увеличения нефтеотдачи пластов на изменение свойств добываемой нефти [текст] / И.А. Гуськова, А.Т. Габдрахманов // Нефтяное хозяйство. - 2011, №4. - С. 101-103. 


\section{References}

1. Guskova, I.A. Preliminary assessment of the results of the development of deposits of domicile deposits in the Republic of Tatarstan. I.A. Guskova, A.T. Gabdrakhmanov, E.V. Levanova, R.I. Muzipov. Http://antat.tatar/en/activity/conferences/documents/Soderganie.pdf (circulation date 13.05.17)

2. Malikov, A. Resources of carbonate oil in Tatarstan reach 1 billion tons http://www.oilru.com/news/403690 (circulation date 13.05.17).

3. Glumov, I.F. Temporary instruction on the application of photocolorimetry of extracted oils to solve geological-engineering problems [text] / I.F. Glumov, A.F. Gilmanshin // Bugulma: TatNII, 1965. - $37 \mathrm{p}$.

4. Gilmanshin, A.F. Nature and causes of the change in time in the value of ksp of oil produced at the Romashkinskoye and Bavlinskoye fields [text] / A.F. Gilmanshin // Proceedings of TatNI-Leningrad: Nedra, 1964. issue VI -C.281-291.

5. Devlikamov V.V. Khabibullin Z.A. Physics of the reservoir: A manual.-Ufa. Ed. Ufims. Neft. Institute, 1986.-82c.

6. Ibatullin, R.R. Increase in oil recovery at a late stage of field development [text] / RR Ibatullin, N.G. Ibragimov, Sh. F. Takhautdinov, RS Khisamov // Theory. Methods. Practice.-M .: OOO NedraBusiness Center, 2004.-292p.

7. Devlikamov, V.V. Optical methods of control over the development of oil deposits [text] / V.V. Devlikamov, I.L. Marhasin, G.A. Babalyan // M .: Nedra, 1970.-160 p.

8. Pat. 2429343 RF, IPC E21B 43/16. Method of developing the oil deposit [text] / NG. Ibragimov, I.A. Guskova, R.R. Ibatullin, A.R. Rakhmanov, A.T. Gabdrakhmanov, M.V. Shvetsov; The applicant and the patent holder of OAO TATNEFT im. V.D. Shashina. - №2010142776 / 03; Claimed. 10/20/10; Publ. 20.09.11, Bul. № 26.

Guskova, I.A. Investigation of the effect of applying methods of increasing oil recovery on the changes in the properties of extracted oil [text] / I.A. Guskova, A.T. Gabdrakhmanov // Oil Industry. 2011, №4. - P. 101-103.

8. Guskova, I.A. Investigation of the effect of applying methods of increasing oil recovery on the changes in the properties of extracted oil [text] / I.A. Guskova, A.T. Gabdrakhmanov // Oil Industry. 2011, №4. - P. 101-103. 